\title{
Arthroscopic Removal of an Intra-Articular Migrating Plant Awn Associated with Septic Shoulder Joint Arthritis in a Dog
}

\author{
Juan J. Camarasa ${ }^{1}$ Olga Travetti ${ }^{1,2}$ Rosario Vallefuoco ${ }^{1}$ \\ ${ }^{1}$ Department of Surgery, Pride Veterinary Centre, Derby, United \\ Kingdom \\ 2 VetCT St John's Innovation Centre, Cambridge, United Kingdom \\ Address for correspondence Juan Jose Camarasa Evaristo, DVM, MSc, \\ Department of Surgery, Pride Veterinary Centre, Riverside Road, \\ DE248HX, Derby, United Kingdom \\ (e-mail: juanjocamarasa@gmail.com).
}

VCOT Open 2020;3:e177-e181.

\begin{abstract}
Keywords

- arthroscopy

- arthritis

- imaging techniques and analysis

- migrating grass awn

- dog

Objective The aim of this study was to describe the clinical presentation, advanced imaging findings and outcomes of arthroscopic treatment of a bacterial septic shoulder arthritis caused by the penetration of a migrating plant awn in a dog.

Case Report A 10-month-old, $11 \mathrm{~kg}$, sexually intact male Cocker Spaniel was diagnosed with septic arthritis of the right scapulohumeral joint. Computed tomography revealed marked articular effusion and thickening of the capsule of the right shoulder joint. Ultrasound of the shoulder identified a bilinear hyperechoic structure located within the joint consistent with a plant (grass) awn. Arthroscopy was used for foreign body removal. Antibiotic treatment was prescribed according to bacteriologic sensitivity tests. Treatment was successful: the dog completely recovered and under high levels of activity showed neither clinical signs nor recurrence of lameness on follow-up at 6 and 24 weeks after surgery.

Conclusion Migrating plant awn can be the cause of septic arthritis in a dog. The combination of advanced imaging techniques and arthroscopy allowed accurate diagnosis, reduced the risk of surgical complications and shortened recovery time in this patient. Considering the benefits of minimally invasive techniques, arthroscopy represents an excellent option for the treatment of dogs with similar intra-articular foreign bodies.
\end{abstract}

\section{Introduction}

Migrating vegetal foreign bodies are a common clinical condition in dogs and may be challenging to diagnose and treat. Plant (grass) awns have been encountered in different locations of the body including the ear canals, ${ }^{1,2}$ respiratory tract and pleural space, ${ }^{1-5}$ sublumbar musculature and retroperitoneal cavity, ${ }^{1,2,6-8}$ reproductive system, ${ }^{9}$ oropharynx, ${ }^{10}$ pericardium, ${ }^{11,12}$ central nervous system, ${ }^{13}$ bladder, ${ }^{14}$ epidural space, ${ }^{15}$ interdigital webs and lower extremities. ${ }^{2,16}$ To the authors' knowledge, intra-articular migration of grass seeds has not yet been reported in the veterinary literature.

received

June 9,2020

accepted after revision

October 22, 2020
DOI https://doi.org/

10.1055/s-0040-1721661. ISSN 2625-2325.
Plant awns can not only cause inflammation on their progression through the tissues but also induce septic reactions as a result of the bacterial or fungal contaminants carried by the seed. ${ }^{13,17}$

Septic arthritis involves microbial infection of the synovium and synovial space and may arise from haematogenous localization, local spread from adjacent tissues and also by direct surgical or traumatic penetration. ${ }^{18}$

The purpose of this report was to describe the clinical presentation, advanced imaging diagnostic findings and outcomes of the arthroscopic treatment of bacterial infectious (c) 2020 Georg Thieme Verlag KG License terms
Rüdigerstraße 14, 70469 Stuttgart,
Germany

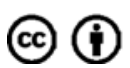


shoulder arthritis caused by the penetration of a migrating vegetal foreign body in a 10-month-old dog.

\section{Case Report}

A 10-month-old, $11 \mathrm{~kg}$, sexually intact male Cocker Spaniel was referred with a 3-day history of acute right forelimb lameness. A grass awn, that had penetrated the skin, had been removed by the referring veterinarian from the right pre-scapular region 2 weeks previously and a course of 1 week of amoxicillin-clavulanate $(15 \mathrm{mg} / \mathrm{kg}$, per os [PO], q12 hours) and meloxicam ( $0.1 \mathrm{mg} / \mathrm{kg}$, PO, q 24 hours) had been prescribed. The superficial wound had healed completely before the dog presented for lameness.

At admission, the general physical and neurological examinations were largely unremarkable. The orthopaedic exam revealed a grade $3 / 5$ lameness of the right forelimb at walk and trot and reduced range of motion in both flexion and extension of the right shoulder joint associated with moderate joint effusion and pain at manipulation. Otherwise, the rest of the orthopaedic examination was unremarkable. No skin lesions or cutaneous fistulous tracts were noticed in the area where the grass seed was previously removed. Complete blood count and serum biochemical analysis were within normal limits. Computed tomography (CT) examination of both shoulder joints was performed under sedation and images were acquired before and after intravenous (IV) contrast medium administration (iohexol $2 \mathrm{~mL} / \mathrm{kg}$, IV). The images were acquired with a 16 multislice helicoid scanner (GE Healthcare CT brightspeed 16 slice scanner, London, United Kingdom). A contiguous 0.6-mm slice acquisition was obtained. Images were processed in a high-resolution algorithm, and re-processed in low-resolu- tion algorithm with a $1.25-\mathrm{mm}$ slice thickness. The image size was $512 \times 512$ and the field of view was big enough to encompass both shoulder and axillary regions $(1809 \times 896)$. After contrast medium administration, the acquisition was repeated and processed in a low-resolution algorithm. Images were viewed in bone window (window width: 2000; window length: 500) and soft tissue window (window width: 350; window length: 40) using a digital image processing software (OsiriX, Medical Imaging DICOM Viewer Software, Pixmeo SARL, Bernex, Switzerland). Multiplanar reformatted images in transverse, sagittal and dorsal planes were generated.

Computed tomography findings were consistent with a marked effusion of the right shoulder joint associated with a thickening of the joint capsule. A linear hypoattenuating lesion in the subscapularis muscle with marked peripheral contrast was noticed $2 \mathrm{~cm}$ proximal to the scapulohumeral joint (-Fig. 1). Neither an intra-articular nor extra-articular foreign body was identified. Nevertheless, the extra-articular lesions appeared to be a fistulous tract from a penetrating foreign body, given the history.

Ultrasonographic examination of the right shoulder joint followed the CT scan. This was performed with a real-time curvilinear array scanner at a transducer frequency of 5 to $8 \mathrm{MHz}$. The evaluation of the scapulohumeral joint confirmed joint effusion and a bilinear hyperechoic structure located within the craniomedial aspect of the joint, compatible with a vegetal foreign body (grass awn) (-Fig. 2).

The right shoulder was then aseptically prepared for arthrocentesis. The synovial fluid showed macroscopically reduced viscosity and turbid appearance. Cytology evaluation was consistent with marked neutrophilic inflammation and low numbers of activated macrophages, but no infectious

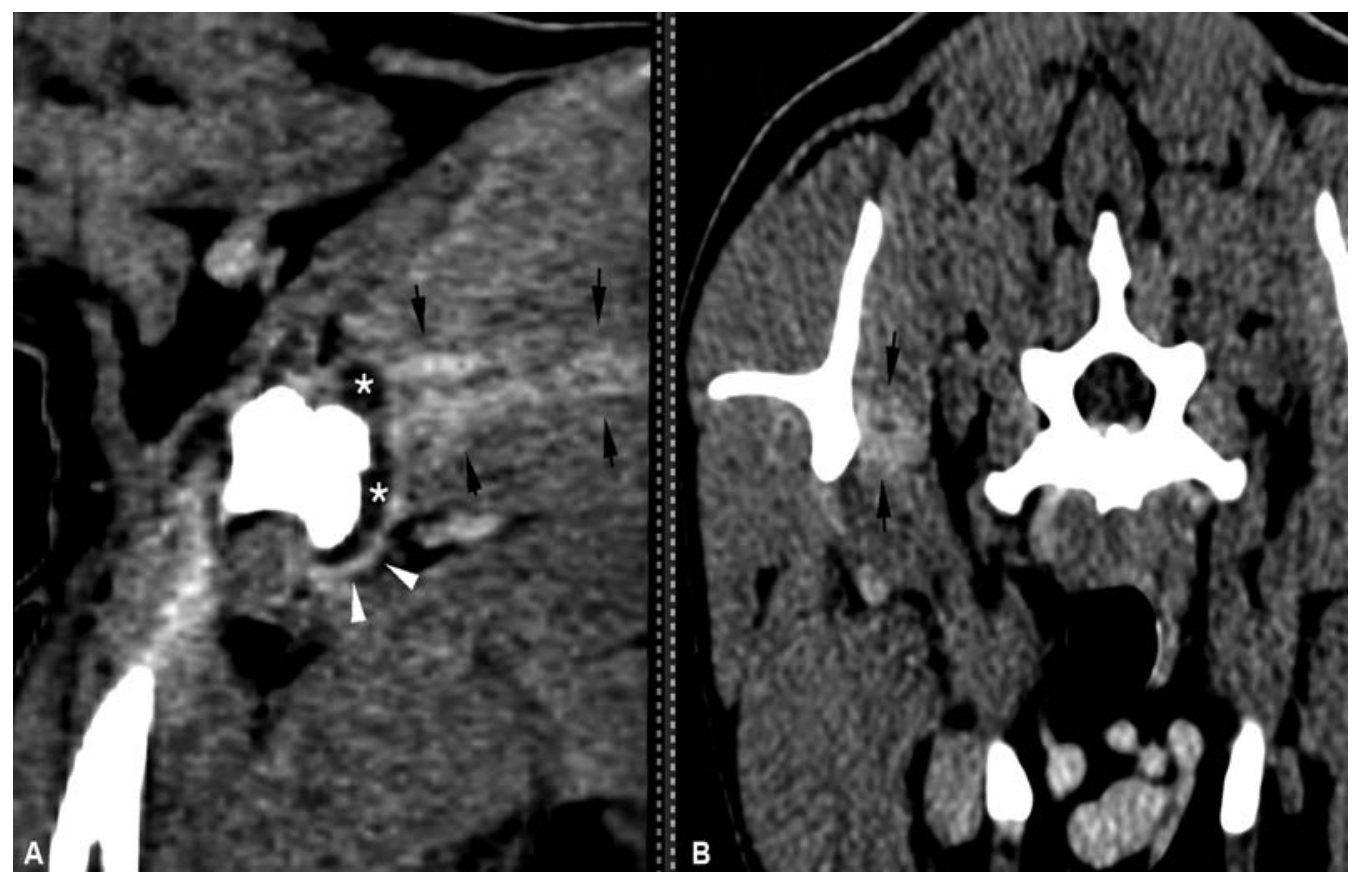

Fig. 1 Transverse computed tomography images at the level of the right shoulder joint (A, B). (A) The asterisks indicate intra-articular distension and the white arrow heads the thickened synovial capsule. (A, B) A linear hypoattenuating lesion with marked peripheral contrast, representing a fistulous tract, can be observed in the subscapularis muscle (black arrows). 


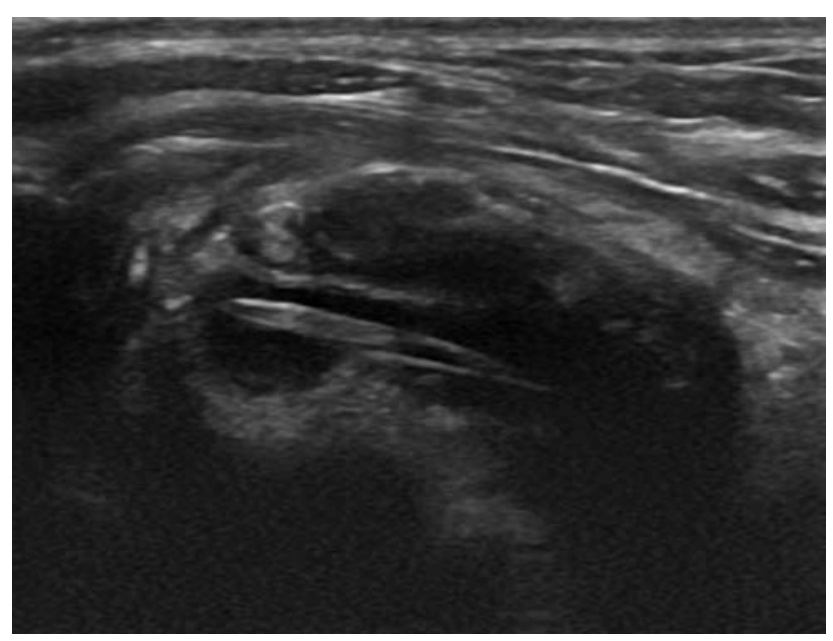

Fig. 2 Longitudinal ultrasound image of the right shoulder joint. A bilinear hyperechoic structure is located within the joint, surrounded by hypoechoic fluid, compatible with joint effusion.

agents were observed. Synovial fluid was submitted for bacteriology culture and sensitivity testing. A presumptive diagnosis of right shoulder septic arthritis due to a migrating plant awn was made and shoulder arthroscopy was planned the day after to remove the foreign body.

General anaesthesia was induced and maintained for the right shoulder arthroscopy. The dog was positioned in left lateral recumbency and the entire right forelimb was aseptically prepared. A standard lateral arthroscopy of the right shoulder was performed with a $10-\mathrm{cm}$, 30degrees locking forward, 2.4-mm arthroscope (KARL STORZ Endoscopy (UK) Ltd. Slough, United Kingdom). The dog received antibiotic medications (amoxicillin-clavulanic $22 \mathrm{mg} / \mathrm{kg}, \mathrm{IV}$ ) and opioids (methadone $0.2 \mathrm{mg} / \mathrm{kg}$, IV) at induction. Joint exploration revealed diffuse moderate synovial inflammation and free intra-articular fibrin clots. Two barbs of a plant awn were found lodged within the proliferative and inflamed synovium in the medial aspect of the joint, medially to the biceps tendon (-Fig. 3). A craniolateral instrument portal was used to insert an arthroscopy grasping forceps (Grasping forceps,

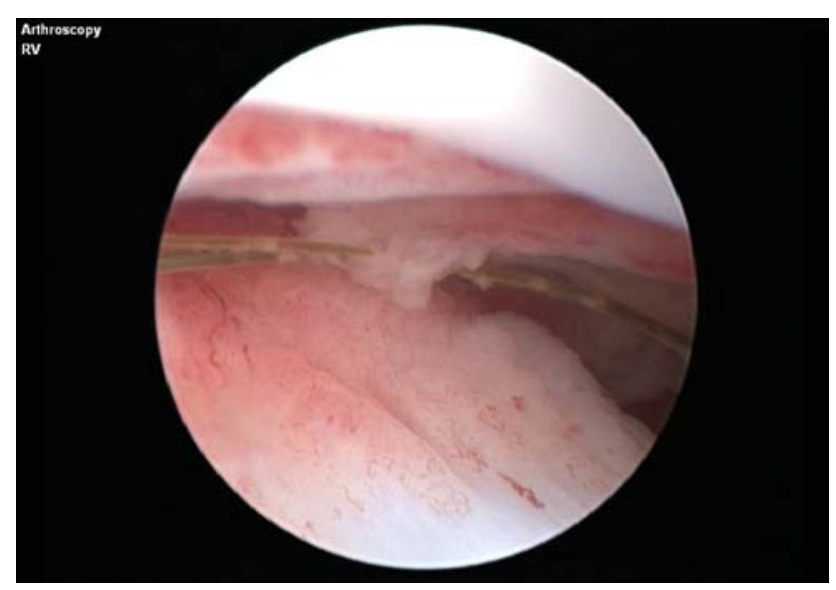

Fig. 3 Arthroscopic view of the right shoulder joint. Two barbs of a grass awn foreign body are seen lodged within the proliferative and inflamed synovium.

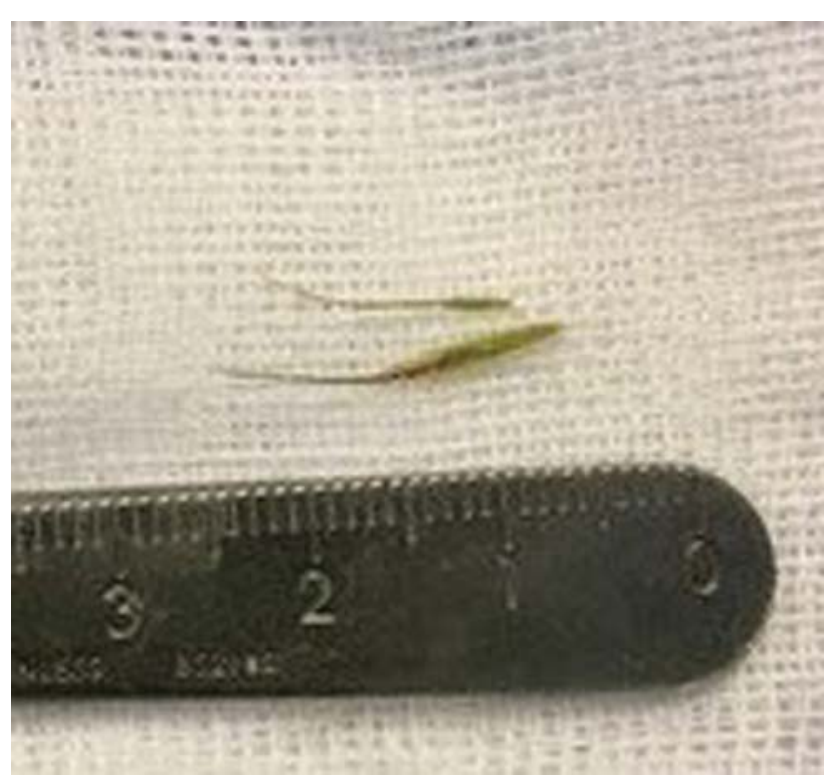

Fig. 4 The grass awn after retrieval.

Veterinary Instrumentation, Sheffield, United Kingdom) to successfully extract the foreign bodies (-Fig. 4). The joint was flushed with Ringer Lactate solution and the skin was closed routinely. Crystalloid fluid (Ringer Lactate, $2 \mathrm{~mL} / \mathrm{kg} / \mathrm{h}$, IV) and analgesia (methadone $0.2 \mathrm{mg} / \mathrm{kg}$, IV and paracetamol $10 \mathrm{mg} / \mathrm{kg}$, PO, q 8 hours) were continued overnight. The dog recovered uneventfully from anaesthesia and was discharged the following day with paracetamol ( $10 \mathrm{mg} / \mathrm{kg}, \mathrm{PO}, \mathrm{q} 8$ hours) for 5 days, meloxicam $(0.1 \mathrm{mg} / \mathrm{kg}$, PO, q 24 hours ) for 10 days and a 4-week course of amoxicillin-clavulanate $(20 \mathrm{mg} / \mathrm{kg}$, PO, q 12 hours). Anaerobic and aerobic microbial culture validated the adequacy of the selected antibiotic medication. A Staphylococcus aureus growth confirmed septic arthritis. The owner was instructed to restrict the exercise of the dog over a period of 6 weeks and gradually increase the level of activity. Follow-up reassessment 2 weeks later was completed by the referring veterinary surgeon, who described a marked improvement in the lameness. The owners were contacted by telephone 6 weeks after foreign body removal and reported the dog to be free of any abnormal clinical signs. Six months after surgery, the referring clinician performed an orthopaedic exam and found absence of lameness, swelling and pain of the previously affected limb, with the dog exercising with normal activity.

\section{Discussion}

To the authors' knowledge, septic arthritis caused by a migrating grass seeds has hitherto not been reported. A grass awn foreign body within the articular space seems unusual indeed and its migrating pattern, penetrating the joint capsule, remains difficult to explain. The backward facing barbed structure of grass awns favours unidirectional advancement and migrating patterns usually follow anatomic planes. ${ }^{2}$ The dense fibrous membrane of the joint capsule, lined with synovium, forms a protective and relatively resistant boundary around the articulating bones that seems difficult to be 
penetrated. We speculate, that in this case, the removal of the originally subcutaneously located grass awn was incomplete and that perhaps manipulations during extraction caused some damage to underlying soft tissue structures, favouring penetrating migration into the joint.

Advanced imaging techniques were essential to identify and localize the foreign body and to eventually retrieve it by arthroscopy, achieving good outcome. ${ }^{19,20}$ Computed tomography has been reported to be useful as a method for localizing lesions produced by the passage of migrating plant parts. ${ }^{1,21-23}$ However, vegetal foreign bodies are difficult to see, because they typically show attenuation similar to the surrounding soft tissues when they absorb body fluid. Secondary signs such as soft tissue inflammation, gas-containing elongated structures or slightly hyperattenuating tracts may be used to estimate the position of the foreign material within the soft tissues. ${ }^{20,22}$ Ultrasound, on the other hand, has shown high accuracy in the diagnosis of migrating grass seeds, due to the ability of identifying distal acoustic shadows associated with linear vegetal structures. ${ }^{4,7,14,19,24,25}$ The combined application of CT and ultrasound substantially increases likelihood of identification and subsequent successful extraction of such foreign bodies. ${ }^{21}$ In the present case, the CT scan alone did not clearly outline the intra-articular foreign body, likely because the plant material, by absorbing synovial fluid, acquired $\mathrm{CT}$ attenuation similar to surrounding tissues, and was therefore invisible. However, the ultrasound examination allowed to outline its shape, form and localization. Computed tomography arthrography could have been also used as an adjuvant technique to try identifying the foreign body, as previously described in canine shoulder arthropathies, since intra-articular contrast medium helps outline the margins of the synovial membrane and the cartilaginous structures. ${ }^{26}$ This technique was not used in our case and a not invasive imaging modality such as ultrasound was preferred.

Diagnostic ultrasonography is well suited to explore soft tissue structures of the shoulder: lesions of the biceps, supraspinatus, infraspinatus and teres minor tendons can be well characterized ${ }^{27}$; joint effusion, articular surface irregularities and the caudal aspect of the humeral head can also be identified. ${ }^{27}$ However, a limitation of ultrasonographic examination of the shoulder is the inability to properly evaluate the structures on the medial side of the joint, where osteochondritis dissecans and glenohumeral ligament lesions are often encountered. ${ }^{27}$

In humans, arthrotomy has shown some limitations in identifying intra-articular foreign bodies, requiring multiple interventions for achieving satisfactory outcomes. ${ }^{28,29}$ The procedure may fail in some cases and carries the risk of acute or late complications. ${ }^{29}$

In human medicine, minimally invasive techniques have shown to provide excellent views of the intra-articular space for successful removal of foreign bodies; thus, avoiding the more invasive arthrotomies with the commonly associated morbidity and soft tissue disruption. ${ }^{30}$ Arthroscopy has also been described as a useful tool for the management of septic arthritis in both humans and animals..$^{18,31,32}$ In our case, arthroscopy allowed extensive exploration of the joint, identification and extraction of the plant awn and thorough joint irrigation with minimal postoperative morbidity. Considering the location of the foreign body in our case, its retrieval would have been difficult and more invasive without the aid of the arthroscopy.

Bacterial-induced arthritis due to penetration of a foreign body is a rare condition in small animals. ${ }^{33,34}$ In this case, Staphylococcus aureus was identified from a synovial sample obtained from the affected joint. This result is similar to other reports were the most commonly isolated bacterial strains from grass awns included Staphylococcus sp., Escherichia coli, Pseudomonas sp. and Streptococci s.p. ${ }^{17,35}$ Systemic antibiotic therapy based on bacterial isolation and sensitivity test for at least 28 days is a standard treatment for septic arthritis, ${ }^{18,36}$ and it was prescribed also in our case. Discontinuation of antimicrobial treatment is usually based on synovial fluid analyses at the end of the antibiotic course. If the cell count has not returned to normal and the neutrophil percentage is above $3 \%$, antimicrobials should be continued until synovial fluid cytology is within normal limits. ${ }^{18,36}$ In this dog, the complete extraction of the grass awn, which was the source of infection, along with the absence of clinical signs on follow-up, justified earlier withdrawal of antibiotic medications.

The extraction of this migrating grass awn warranted reporting, on one hand, because of its unusual location, lodging intra-articularly within the scapulohumeral joint, and on the other, because advanced imaging techniques and mini-invasive surgical extraction resulted in swift and complete recovery.

\section{Authors' Contributions}

R.V. performed the surgical procedure. All authors contributed to the drafting and revision of the manuscript.

Conflict of Interest

None declared.

\section{References}

1 Vansteenkiste DP, Lee KC, Lamb CR. Computed tomographic findings in 44 dogs and 10 cats with grass seed foreign bodies. J Small Anim Pract 2014;55(11):579-584

2 Brennan KE, Ihrke PJ. Grass awn migration in dogs and cats: a retrospective study of 182 cases. J Am Vet Med Assoc 1983;182 (11):1201-1204

3 Demetriou JL, Foale RD, Ladlow J, McGrotty Y, Faulkner J, Kirby BM. Canine and feline pyothorax: a retrospective study of 50 cases in the UK and Ireland. J Small Anim Pract 2002;43(09): 388-394

4 Caivano D, Bufalari A, Giorgi ME, et al. Imaging diagnosistransesophageal ultrasound-guided removal of a migrating grass awn foreign body in a dog. Vet Radiol Ultrasound 2014;55(05): 561-564

5 Lotti U, Niebauer GW. Tracheobronchial foreign bodies of plant origin in 153 hunting dogs. Comp Cont Edu 1992;14:900-905

6 Frendin J, Funkquist B, Hansson K, Lönnemark M, Carlsten J. Diagnostic imaging of foreign body reactions in dogs with diffuse back pain. J Small Anim Pract 1999;40(06):278-285

7 Birettoni F, Caivano D, Rishniw M, et al. Preoperative and intraoperative ultrasound aids removal of migrating plant material causing iliopsoas myositis via ventral midline laparotomy: a study of 22 dogs. Acta Vet Scand 2017;59(01):12 
8 Moretti G, Birettoni F, Caivano D, et al. Mini-invasive approach for removal of iliopsoas migrating grass awns with an atraumatic wound retractor. J Small Anim Pract 2019

9 Agut A, Carrillo JD, Anson A, Belda E, Soler M. Imaging diagnosisurethrovaginal fistula caused by a migrating grass awn in the vagina. Vet Radiol Ultrasound 2016;57(03):E30-E33

10 Hinken K, Kaiser S, Hinken M. Computed tomographic imaging of plant foreign bodies associated with oropharyngeal injuries. Kleintierpraxis 2010;55:5-13

11 Aronson LR, Gregory CR. Infectious pericardial effusion in five dogs. Vet Surg 1995;24(05):402-407

12 Caivano D, Birettoni F, Marchesi MC, et al. Septic pericarditis and cardiac tamponade caused by migrating intrathoracic grass awn in an English Setter dog. Isr J Vet Med 2019;74:82-87

13 Dennis MM, Pearce LK, Norrdin RW, Ehrhart EJ. Bacterial meningoencephalitis and ventriculitis due to migrating plant foreign bodies in three dogs. Vet Pathol 2005;42(06):840-844

14 Cherbinsky O, Westropp J, Tinga S, Jones B, Pollard R. Ultrasonographic features of grass awns in the urinary bladder. Vet Radiol Ultrasound 2010;51(04):462-465

15 Linon E, Geissbühler U, Karli P, Forterre F. Atlantoaxial epidural abscess secondary to grass awn migration in a dog. Vet Comp Orthop Traumatol 2014;27(02):155-158

16 Fauchon E, Lassaigne C, Ragetly G, Gomes E. Ultrasound-guided removal of vegetal foreign bodies in the lower extremities of dogs: a retrospective study of 19 cases. Vlaams Diergeneeskd Tijdschr 2017;86:285-290

17 Flisi S, Dall'Aglio M, Spadini C, Cabassi CS, Quintavalla F. Microbial isolates from vegetable foreign bodies inhaled by dogs. Vet Med Int 2018;2018:3089282

18 InnesJF. Arthritis. In: Tobias KM, Johnston SA, eds. Veterinary Surgery: Small Animal. 2nd edition. Missouri: Elsevier; 2018:1265-1299

19 Gnudi G, Volta A, Bonazzi M, Gazzola M, Bertoni G. Ultrasonographic features of grass awn migration in the dog. Vet Radiol Ultrasound 2005;46(05):423-426

20 Schultz RM, Zwingenberger A. Radiographic, computed tomographic, and ultrasonographic findings with migrating intrathoracic grass awns in dogs and cats. Vet Radiol Ultrasound 2008;49 (03):249-255

21 Attanasi G, Laganga P, Rossi F, et al. Use of ultrasonography and CT in the diagnosis and treatment of plant foreign bodies in 56 dogs. Riv Uff Della SCIVAC. 2011;25:25-30

22 Bouabdallah R, Moissonnier P, Delisle F, et al. Use of preoperative computed tomography for surgical treatment of recurrent draining tracts. J Small Anim Pract 2014;55(02):89-94
23 Baudin Tréhiou C, Gibert S, Sériot P, Dunié-Mérigot A, Blond L. CT is helpful for the detection and presurgical planning of lung perforation in dogs with spontaneous pneumothorax induced by grass awn migration: 22 cases. Vet Radiol Ultrasound 2020;61 (02):157-166

24 Della Santa D, Rossi F, Carlucci F, Vignoli M, Kircher P. Ultrasoundguided retrieval of plant awns. Vet Radiol Ultrasound 2008;49 (05):484-486

25 Caivano D, Birettoni F, Rishniw M, et al. Ultrasonographic findings and outcomes of dogs with suspected migrating intrathoracic grass awns: 43 cases (2010-2013). J Am Vet Med Assoc 2016;248 (04):413-421

26 Eivers CR, Corzo-Menéndez N, Austwick SH, et al. Computed tomographic arthrography is a useful adjunct to survey computed tomography and arthroscopic evaluation of the canine shoulder joint. Vet Radiol Ultrasound 2018;59(05):535-544

27 Rochat MC. The shoulder. In: Tobias KM, Johnston SA, eds. Veterinary Surgery: Small Animal. 2nd edition. Missouri: Elsevier; 2018:800-820

28 Said HG, Masoud MA, Yousef HA, Imam HM. Multidetector CT for thorn (wooden) foreign bodies of the knee. Knee Surg Sports Traumatol Arthrosc 2011;19(05):823-825

29 Callegari L, Leonardi A, Bini A, et al. Ultrasound-guided removal of foreign bodies: personal experience. Eur Radiol 2009;19(05): 1273-1279

30 Raval P, Vijayan A, Jariwala A. Arthroscopic retrieval of over 100 loose bodies in shoulder synovial chondromatosis: a case report and review of literature. Orthop Surg 2016;8(04):511-515

31 Luther JF, Cook JL, Stoll MR. Arthroscopic exploration and biopsy for diagnosis of septic arthritis and osteomyelitis of the coxofemoral joint in a dog. Vet Comp Orthop Traumatol 2005;18(01): 47-51

32 Shukla A, Beniwal SK, Sinha S. Outcome of arthroscopic drainage and debridement with continuous suction irrigation technique in acute septic arthritis. J Clin Orthop Trauma 2014;5(01):1-5

33 Bennett D, Taylor DJ. Bacterial infective arthritis in the dog.J Small Anim Pract 1988;29(04):207-230

34 Clarke SP, Ferguson JF. Bacterial infective arthritis following a penetrating stick injury of the stifle joint in a dog. J Small Anim Pract 2012;53(08):483-486

35 Marchevsky AM, Read RA. Bacterial septic arthritis in 19 dogs. Aust Vet J 1999;77(04):233-237

36 Clements DN, Owen MR, Mosley JR, Carmichael S, Taylor DJ, Bennett D. Retrospective study of bacterial infective arthritis in 31 dogs. J Small Anim Pract 2005;46(04):171-176 